\title{
Las comunicaciones por videoconferencia de los internos con el abogado defensor o con el abogado expresamente llamado en relación con asuntos penales
}

Videoconferencing of inmates with the defence lawyer or with the lawyer expressly called in relation to criminal matters

\section{Pablo García Molina ${ }^{1}$}

Universidad de Cádiz - Cádiz/España

pablo.garciamolina@uca.es

http://orcid.org/0000-0003-2101-8472

\begin{abstract}
ResUMen: El uso de la videoconferencia en la Administración de Justicia española, y, más concretamente, en el proceso penal español, no es algo novedoso, ni siquiera en los centros penitenciarios, donde desde hace más de una década se hace uso de esta tecnología para facilitar la práctica de algunas actuaciones judiciales. Sin embargo, su uso para otros fines es completa o prácticamente inexistente, a pesar de que puede ser muy adecuada, entre otras cosas, para facilitar las comunicaciones entre el interno y sus familiares, para que se le preste al interno asistencia médica, o para las comunicaciones por videoconferencia de los internos con el abogado defensor o con el abogado expresamente llamado en relación con asuntos penales. Precisamente, este trabajo se centra en esta última posibilidad al analizar si actualmente este tipo de comunicaciones está regulada o no en la normativa penitenciaria española, si existen antecedentes al respecto en nuestro país, qué ventajas y deseventajas presenta, cómo ha de desarrollarse y qué garantías debe tener.
\end{abstract}

PALABRAS-CLAVE: comunicaciones; videoconferencia; internos; abogado.

ABSTRACT: The use of videoconferencing in the Spanish Administration of Justice,

1 Profesor Sustituto Interino de Derecho Procesal de la Universidad de Cádiz. 
and more specifically, in the Spanish criminal process, is not something new, not even in prisons, where for more than a decade this technology has been used to facilitate the practice of some judicial proceedings. However, its use for other purposes is complete or practically non-existent, although it may be very appropriate, among other things, to facilitate communications between the inmate and his family, to provide the inmate with medical assistance, or for videoconferencing of inmates with the defence lawyer or with the lawyer expressly called in relation to criminal matters. Precisely, this work focuses on the latter possibility when analysing whether this type of communication is currently regulated or not in the Spanish penitentiary regulations, if there are antecedents in this respect in our country, what advantages and disadvantages does it present, how it must be developed and what guarantees it must have.

KEYwORDS: communications; videoconferencing; inmates; lawyer.

SUMARIO: Introducción; 1. Regulación; 2. Antecedentes; 3. Ventajas y desventajas; 4. Desarrollo; 4.1. Solicitud; 4.2. Intervinientes; 4.3. Identificación de los intervenientes; 4.4. Lugar; 4.5. Tiempo; 4.6. Otras cuestiones; Conclusiones; Bibliografía.

\section{INTRODUCCIÓN}

La videoconferencia es un sistema que permite la comunicación bidireccional y simultánea de la imagen y el sonido y la interacción visual, auditiva y verbal entre dos personas o grupos de personas geográficamente distantes (arts. 229.3 de la Ley Orgánica 6/1985, de 1 de julio, del Poder Judicial [en adelante, LOPJ] y 325 y 731 bis. del Real Decreto de 14 de septiembre de 1882 por el que se aprueba la Ley de Enjuiciamiento Criminal [en adelante, LECrim]) $)^{2}$.

La idea original del uso de la videoconferencia en los centros penitenciarios era facilitar la práctica de diligencias de investigación y la celebración de juicios orales, idea en torno a la cual, como veremos

2 El Diccionario de la lengua española define la palabra videoconferencia como la "comunicación a distancia entre dos o más personas, que pueden verse y oírse a través de una red”. 
a continuación, se ha desarrollado el uso de esta tecnología en la Administración de Justicia ${ }^{3}$.

Así, por ejemplo, cabría hacer uso de la videoconferencia para la práctica de algunas actuaciones judiciales que se desarrollan durante la instrucción o el juicio oral como, por ejemplo, para celebrar ruedas de reconocimiento ${ }^{4}$; vistas de prórrogas de prisión ${ }^{5}$; algunas diligencias de prueba en el juicio oral; o, incluso, para las entrevistas de los fiscales,

3 Para una panorámica general sobre el uso de la videoconferencia en la Administración de Justicia española vid. GUTIÉRREZ BARRENENGOA, Ainhoa. La utilización de la videoconferencia en la Administración de Justicia. En: HERRÁN ORTIZ, Ana Isabel; EMALDI CIRIÓN, Aitziber; ENCISO SANTOCILDES, Marta (Eds.), Derecho y Nuevas Tecnologías. Bilbao: Universidad de Deusto, 2010. v. 2, p. 121-134; y VALBUENA GONZÁLEZ, Félix. Proceso penal y videoconferencia. En: HERRÁN ORTIZ, Ana Isabel; EMALDI CIRIÓN, Aitziber; ENCISO SANTOCILDES, Marta (Eds.), Derecho y Nuevas Tecnologías. Bilbao: Universidad de Deusto, 2010. v. 3, p. 83-95.

4 Vid. la Sentencia 669/2017, de 11 de octubre, de la Sección $1^{\text {a }}$ de la Sala de lo Penal del Tribunal Supremo, y la Sentencia 211/2016, de 29 de abril, de la Sección $3^{\text {a }}$ de la Audiencia Provincial de Córdoba, en las que se narran sendos casos en los que se realizan ruedas de reconocimiento a través de videoconferencia con el centro penitenciario. En contra del uso de esta tecnología, en este caso, en relación con un sujeto que se encontraba en libertad, se pronuncia el Auto 536/2015, de 23 de diciembre, de la Sección $3^{\text {a }}$ de la Audiencia Provincial de Cantabria, según el cual, "de pretenderse situar a todas las personas que formasen la rueda en una sala de vistas y proceder desde allí al reconocimiento por videoconferencia, existiría el óbice de tener que utilizar grandes angulares para recoger al mismo tiempo la imagen de todas las personas que conformasen la rueda, lo que supondría minimizar sus imágenes, con la posibilidad de visionado irregular de sus características físicas, al estar las personas a una gran distancia focal del objetivo -la relativización de las dimensiones a la que se refiere el Juez instructor en el auto resolutorio del previo recurso de reforma-. Y siempre podría alegar el Letrado defensor del recognoscible que no ha estado presente en el otro punto de la videoconferencia [...], que no ha podido observar si se veía o no bien a los recognoscibles y que no ha podido acotar preguntando al recognosciente lo que estimara procedente sobre la persona reconocida, postulando después la nulidad de la prueba. Pero es que, a mayor abundamiento, aunque hubiere sistemas que permitieran un visionado claro y amplio de las personas a reconocer, siempre será competencia del juez instructor y del Letrado/a de la Administración de Justicia del Juzgado la conformación de la rueda y la supervisión de la práctica de la diligencia”.

5 Esto ha sido utilizado por la Audiencia Provincial de Alicante en diversas ocasiones. 
de menores o de adultos; y de los jueces, de menores o de vigilancia penitenciaria, con los internos en un centro de internamiento de menores infractores o en un centro penitenciario ${ }^{6}$. Todos estos casos tienen en común que uno de los sujetos que intervienen en la comunicación (concretamente, el sujeto pasivo del proceso penal) se encontraría interno en un centro penitenciario como preso preventivo o como penado, mientras que el resto de los intervinientes (juez, letrado de la Administración de Justicia, fiscal, abogados, testigos, peritos, etc.) se encontrarían fuera del mismo.

Sin embargo, su uso para otros fines es completa o prácticamente inexistente, a pesar de que puede ser muy adecuado, entre otras cosas, para facilitar las comunicaciones entre el interno y sus familiares, para que se le preste al interno asistencia médica, o para las comunicaciones por videoconferencia de los internos con el abogado defensor o con el abogado expresamente llamado en relación con asuntos penales, lo que contribuiría a garantizar el ejercicio del derecho a la defensa y a la asistencia de letrado, finalidad que, aunque actualmente no está prevista

6 El Plan de Implantación del Sistema de Videoconferencia del Ministerio de Justicia de 4 de diciembre de 2001, preveía entre los usos del sistema de videoconferencia para la Administración de Justicia las entrevistas de los Jueces de Vigilancia Penitenciaria con los reclusos. Más recientemente, el art. 675 de la Propuesta de texto articulado de Ley de Enjuiciamiento Criminal de 2013, preveía expresamente que el interno en un centro penitenciario, cumpliendo condena o en situación de prisión preventiva, tenía derecho al menos cada tres meses a mantener una entrevista personal o mediante videoconferencia con el titular del Tribunal de Vigilancia Penitenciaria. La posibilidad de que el contacto pueda facilitarse a través de videoconferencia se recoge expresamente en la página web de la Secretaría General de Instituciones Penitenciarias, disponible en http://www.iipp.es/web/portal/laVidaEnPrision/derechosDeberes/Derechos/juzgadoVigilancia.html (consultado el 1 de julio de 2019). Asimismo, el Plan de Implantación del Sistema de Videoconferencia del Ministerio de Justicia de 4 de diciembre de 2001, preveía entre los usos del sistema de videoconferencia para la Administración de Justicia, entre otras cuestiones, las entrevistas a menores en centros de internamiento por las Fiscalías o Juzgados de Menores. Más recientemente, la Instrucción 3/2002, de 1 de marzo, de la Fiscalía General del Estado, sobre actos procesales que pueden celebrarse a través de videoconferencia, preveía la posibilidad de utilizar la videoconferencia para actos no estrictamente procesales (v. gr. la entrevista del Fiscal con internos en centros penitenciarios). 
en nuestra normativa penitenciaria, entendemos necesaria ${ }^{7}$, motivo por el cual la estudiaremos a continuación con detalle en este trabajo.

En este sentido no hemos de olvidar que los considerandos 23 y 44 de la Directiva 2013/48/UE del Parlamento Europeo y del Consejo de 22 de octubre de 2013 sobre el derecho a la asistencia de letrado en los procesos penales y en los procedimientos relativos a la orden de detención europea, y sobre el derecho a que se informe a un tercero en el momento de la privación de libertad y a comunicarse con terceros y con autoridades consulares durante la privación de libertad, dicen que tanto los sospechosos o acusados como las personas reclamadas deben tener derecho a comunicarse con el letrado que los represente. Esta comunicación puede tener lugar en cualquier momento del proceso, inclusive antes de ejercer el derecho a reunirse con el letrado. Los Estados miembros pueden adoptar disposiciones prácticas sobre la duración, la frecuencia y los medios de dicha comunicación, incluido el uso de la videoconferencia y otras tecnologías de la comunicación con el fin de que pueda tener lugar tal comunicación, siempre que dichas disposiciones prácticas no vayan en detrimento del ejercicio efectivo ni del contenido esencial del derecho de esas personas a comunicarse con sus letrados.

Esta Directiva fue traspuesta al Derecho interno por la Ley Orgánica 13/2015, de 5 de octubre, de modificación de la Ley de Enjuiciamiento Criminal para el fortalecimiento de las garantías procesales y la regulación de las medidas de investigación tecnológica, que, aunque ha dado lugar a algunos avances en relación con el ejercicio del derecho a la defensa y a la asistencia de letrado ${ }^{8}$, no prevé expresamente el uso de la videoconferencia u otras tecnologías de la comunicación para que tanto los sospechosos o acusados como las personas reclamadas puedan ejercer su derecho a

7 En el mismo sentido se pronuncia JORDÁN DÍAZ-RONCERO, María José. Análisis de la implantación y eficacia de la videoconferencia en el proceso penal español: hacia una modernización de nuestro sistema de justicia penal. Tesis Doctoral (Programa de Doctorado en Derecho, Empresa y Justicia) - Universidad de Valencia, Valencia, 2014, p. 471. Disponible en: <http://roderic. uv.es/handle/10550/44107>. Consultado el: 1 jul. 2019.

8 Como, por ejemplo, lo dispuesto en el art. 520.2.c) LECrim, que prevé que, en caso de que, debido a la lejanía geográfica no sea posible de inmediato la asistencia de letrado, debe facilitarse al detenido comunicación telefónica o por videoconferencia con aquel, salvo que dicha comunicación sea imposible. 
comunicarse con el letrado que los represente en cualquier momento del proceso a través de estos medios mientras se encuentren internos como presos preventivos o penados en un centro penitenciario.

\section{Regulación}

La implantación de la videoconferencia en la Administración de Justicia española se produjo a partir del año 2002 y se vio reflejada en la Ley Orgánica 13/2003, de 24 de octubre, de reforma de la Ley de Enjuiciamiento Criminal en materia de prisión provisional, que se aprovechó para introducir esta tecnología de forma expresa en el proceso. No obstante, ello no quiere decir que anteriormente no se utilizase, lo que se hacía, sin cobertura legal expresa, con base en lo dispuesto en el art. 230.1 LOPJ, que, en su redacción actual, dispone que los juzgados y tribunales y las fiscalías están obligados (en la anterior redacción era potestativo) a utilizar cualesquiera medios técnicos, electrónicos, informáticos y telemáticos, puestos a su disposición para el desarrollo de su actividad y ejercicio de sus funciones ${ }^{9}$.

El uso de la videoconferencia en la Administración de Justicia dio lugar a que el 17 de mayo de 2006 se suscribiese un acuerdo interdepartamental, entre los Ministerios de Justicia e Interior, para la implantación de un sistema de comunicaciones, mediante videoconferencia, entre los centros penitenciarios y las sedes de los Jugados, Tribunales y Ministerio Fiscal, para realizar actuaciones judiciales y comparecencias ante órganos judiciales a través de videoconferencia, de acuerdo con lo dispuesto en los arts. 229.3 LOPJ y 325 LECrim $^{10}$.

9 En relación con la regulación del uso de los sistemas de videoconferencia en la Administración de Justicia, la disposición final tercera de la Ley 18/2011, de 5 de julio, reguladora del uso de las tecnologías de la información y la comunicación en la Administración de Justicia, establecía que el Gobierno debía presentar un proyecto de ley que regulase de manera integral el uso de los sistemas de videoconferencia en la Administración de Justicia, circunstancia que, al menos hasta el momento, no se ha producido.

10 Vid. la Instrucción 2/2007, de 30 de enero, de la Dirección General de Instituciones Penitenciarias, p. 1. 
Sin embargo, ni en la Ley Orgánica 1/1979, de 26 de septiembre, General Penitenciaria (en adelante, LOGP) ni en el Real Decreto 190/1996, de 9 de febrero, por el que se aprueba el Reglamento Penitenciario (en adelante, RP) se regula el uso de la videoconferencia en el ámbito penitenciario. Tanto una norma como otra parten de que lo normal es que las comunicaciones se realicen de forma oral (presencialmente) y escrita. No obstante, el art. 51.4 LOGP sí prevé expresamente que las comunicaciones previstas en este artículo puedan efectuarse telefónicamente en los casos y con las garantías que se determinen en el $\mathrm{RP}$, lo que nos hace pensar que el legislador concibió las mismas como algo excepcional o novedoso, dado que, en caso contrario, no hubiese hecho mención expresa a esta posibilidad.

Concretamente, las comunicaciones telefónicas se regulan en el art. 47 RP, según el cual, puede autorizarse la comunicación telefónica de los internos, entre otros casos, cuando el interno haya de comunicar algún asunto importante al abogado defensor (art. 47.1.b RP). Para ello, se dice que el interno que desee comunicar telefónicamente con otra persona, debe solicitarlo al Director del establecimiento (art. 47.2 RP), quien, previa comprobación de los mencionados requisitos, autorizará, en su caso, la comunicación y señalará la hora en que deba celebrarse (47.3 RP).

La implantación del sistema de videoconferencia sí se regula en la Instrucción 2/2007, de 30 de enero, de la Dirección General de Instituciones Penitenciarias, que, no obstante, a pesar de que sí regula expresamente el uso de esta tecnología para la celebración de actuaciones judiciales, de comunicaciones con familiares y de consultas médicas ${ }^{11}$, no

11 Vid. http://www.institucionpenitenciaria.es/web/portal/administracionPenitenciaria/TecnologiasInformacion/CalidadServicios.html y http://www. institucionpenitenciaria.es/web/portal//laVidaEnPrision/relacionesExterior/telefono.html (consultados el 1 de julio de 2019). A mayor abundamiento sobre el uso de la videoconferencia para las comunicaciones con familiares y consultas médicas vid. FERNÁNDEZ DÍAZ, Carmen Rocío. Internet Behind Bars: Reality or Utopia? En: OLIVEIRA, Lídia; GRAÇA, Daniela (eds.). Infocommunication Skills as a Rehabilitation and Social Reintegration Tool for Inmates. Hershey: IGI Global, 2019. p. 1-23; MARCOS MADRUGA, Florencio de. Las nuevas tecnologías en los centros penitenciarios y sus implicaciones jurídicas. En: MATA Y MARTÍN, Ricardo M. (Dir.); JAVATO MARTÍN, Antonio María (Coord.). Sistema penitenciario y nuevas tecnologias. Valladolid: 
contempla la posibilidad de hacer uso de la misma para las comunicaciones de los internos con el abogado defensor o con el abogado expresamente llamado en relación con asuntos penales ${ }^{12}$.

\section{Antecedentes}

Para examinar los antecedentes de las comunicaciones por videoconferencia de los internos con el abogado defensor o con el abogado expresamente llamado en relación con asuntos penales, hemos de distinguir entre lo que sucede en la comunidad autónoma de Cataluña, que es la única que tiene trasferidas las competencias en materia penitenciaria, y lo que sucede en el resto de España, donde las competencias sobre instituciones penitenciarias recaen en el Estado y no en las comunidades autónomas ${ }^{13}$, por lo que, en principio, todo depende de lo que acuerde la Secretaría General de Instituciones Penitenciarias.

Lex Artis, 2014. p. 239-241; MARTÍN MORAL, María Flora. La utilización del sistema de videoconferencia en el marco de las instituciones penitenciarias. En: MATA Y MARTÍN, Ricardo M. (Dir.); JAVATO MARTÍN, Antonio María (Coord.). Sistema penitenciario y nuevas tecnologias. Valladolid: Lex Artis, 2014. p. 45-60; y VIDA FERNÁNDEZ, José. Análisis y propuestas para garantizar el derecho a la asistencia sanitaria de los internos en instituciones penitenciarias. La Ley Penal: Revista de Derecho Penal, Procesal y Penitenciario, Madrid, n. 62, p. 1-19, 2009.

12 JORDÁN DÍAZ-RONCERO, María José, Análisis de la implantación..., cit., pp. 472 y 473, entiende que, aunque de la Instrucción 2/2007, de 30 de enero, de la Dirección General de Instituciones Penitenciarias se extrae que esta comunicación a través de videoconferencia entre abogado e interno no podría mantenerse, dado que ni la LOGP ni el RP lo prohíben, "atendiendo a situaciones adversas que impidan una entrevista que por razones de estrategia procesal relacionadas con el derecho de defensa y de asistencia letrada no puedan ser aplazadas, es obligatorio permitir la reunión por videoconferencia entre abogado e interno en centro penitenciario, pues lo contrario, negar esta petición del letrado o del recluso, implicaría vulneración del derecho de defensa y de la asistencia letrada consagrados ambos en el art. 24.2 CE”.

En el caso de la comunidad autónoma de Andalucía, a pesar de que, según su Estatuto de Autonomía, corresponde a la comunidad autónoma la competencia ejecutiva en materia penitenciaria (art. 67.3 de la Ley Orgánica 2/2007, de 19 de marzo, de reforma del Estatuto de Autonomía para Andalucía), y pese a que al mes siguiente de la entrada en vigor de este Estatuto se debía designar una Comisión Mixta Paritaria Gobierno-Junta de Andalucía que 
Hasta ahora, en España, dos son los antecedentes del uso de la videoconferencia para las comunicaciones entre abogados e internos, precisamente, uno en cada uno de estos ámbitos.

El primero lo encontramos en la comunidad autónoma de Cataluña, donde ya se está implementando un "Servicio de Videoconferencias con centros penitenciarios" para reducir a la mitad las 37.000 visitas presenciales que se hacen cada año entre abogados e internos. Este servicio se puso en marcha tras una prueba piloto que conectó el Centre Penitenciari Quatre Camins (La Roca del Vallés, Barcelona) con el Ilustre Colegio de la Abogacía de Barcelona. Se trata de un servicio que ha puesto en marcha el Ilustre Colegio de la Abogacía de Barcelona conjuntamente con la Dirección General de Servicios Penitenciarios y que garantiza la seguridad y la confidencialidad de esta comunicación ${ }^{14}$. Actualmente, este servicio, pionero en Cataluña y en el resto del Estado, está disponible en nueve centros penitenciarios ${ }^{15} \mathrm{y}$ tres centros educativos de justicia

regulara el proceso, el tiempo y las condiciones de traspaso de las competencias propias de la comunidad autónoma, conforme al presente Estatuto; y que determinara el traspaso de medios personales y materiales necesarios para el ejercicio de tales competencias (número uno de la disposición transitoria primera), lo cierto es que en materia penitenciaria, ningún traspaso de competencia se ha llevado a cabo hasta la fecha. No obstante, recientemente, el 30 de abril de 2019, el Grupo Parlamentario Adelante Andalucía del Parlamento de Andalucía presentó una Proposición no de Ley en Pleno relativa a desarrollo del Estatuto de Autonomía y la competencia de ejecución penitenciaria (Expediente: 11-19/PNLP-000039, número de registro 111913203), disponible en http://www.parlamentodeandalucia.es/webdinamica/portal-web-parlamento/actividadparlamentaria/todaslasiniciativas/porproponente.do?numexp=11-19/PNLP-000039\&accion=Ver\%20 iniciativas $\&$ proponente $=$ Grupo $\% 20$ parlamentario\&legislatura $=11 \&$ indi$\mathrm{ce}=510 \&$ prop $=457$ (consultado el 1 de julio de 2019).

14 Según se dice en la página web del Ilustre Colegio de la Abogacía de Barcelona, "antes de la puesta en funcionamiento del Servicio, se ha llevado a cabo estudio para garantizar la seguridad de la comunicación en forma de videoconferencia. El sistema ha sido revisado y validado por el Centro de Seguridad de la Información de Cataluña". Vid. http://www.icab.es/?go=eaf9d1a0ec5f1dc58757ad6cffdacedb1a58854a600312ccb08705c7052b3548defa77ffbeed6568fa96900438d42b6146cb02bd41ffe8d8 (consultado el 1 de julio de 2019).

15 Concretamente, en los centros penitenciarios de Quatre Camins (La Roca del Vallés, Barcelona); Brians-1 (San Esteban de Sasroviras, Barcelona); Brians-2 (San Esteban de Sasroviras, Barcelona); Puig de les Basses (Figueras, Gerona); 
juvenil ${ }^{16}$, con los que se pueden llevar a cabo las videoconferencias desde la sede del Ilustre Colegio de la Abogacía de Barcelona.

Para examinar el segundo antecedente tenemos que remontarnos al año 2017, cuando el Defensor del Pueblo incoó un expediente con la finalidad de conocer si en el ámbito de actuación de la Secretaría General de Instituciones Penitenciarias se había producido alguna iniciativa análoga a la que por aquellas fechas estaba produciéndose en el ámbito de gestión de la Administración penitenciaria de Cataluña: el establecimiento de un sistema de comunicación de letrados con personas privadas de libertad a través de videoconferencia. El Defensor del Pueblo, tras constatar la falta de interés de la Secretaría General de Instituciones Penitenciarias por este asunto, pese a que sí hay, al menos, un aparente interés político en ello ${ }^{17}$, recomienda "facilitar las comunicaciones previstas en el artículo 51 de la Ley Orgánica General Penitenciaria entre letrados y personas privadas de libertad, mediante sistemas de videoconferencia, que conecten los colegios de abogados y los centros penitenciarios, de modo que los letrados designados para prestar el servicio de asistencia jurídica gratuita puedan comunicarse con las personas privadas de libertad beneficiarias de este derecho, sin necesidad de desplazarse a los centros penitenciarios" ${ }^{\prime 18}$.

No obstante, aunque a nivel estatal no hay una iniciativa clara en estas cuestiones, sí ha habido alguna iniciativa particular de algún

Lledoners (San Juan de Torruella, Barcelona); Mas d'Enric (El Catllar, Tarragona); Dones (Barcelona, Barcelona); Joves (La Roca del Vallés, Barcelona); Ponent (Lérida, Lérida).

16 Concretamente, en los centros educativos de justicia juvenil de l'Alzina ( $\mathrm{Pa}$ lau de Plegamans, Barcelona); Can Llupià (Barcelona, Barcelona) y El Segre (Lérida, Lérida).

17 Vid. el Diario de Sesiones del Congreso de los Diputados, Comisiones, Interior, Sesión n. 39, celebrada el jueves, 13 de diciembre de 2018, n. 691, p. 8, donde se dice que "uno de los objetivos de esta Administración es potenciar la administración digital y las nuevas tecnologías, y en este ámbito, en concreto, para favorecer [...] las videoconferencias entre los internos y sus abogados".

18 Vid. la recomendación del Defensor del Pueblo de 28 de diciembre de 2018 a la Secretaría General de Instituciones Penitenciarias, disponible en https:// www.defensordelpueblo.es/resoluciones/comunicacion-entre-los-internos-en-centros-penitenciarios-y-sus-abogados-mediante-videoconferencia/ (consultado el 1 de julio de 2019). 
Colegio de Abogados en desarrollar esta cuestión. Concretamente, en febrero de 2019 la Secretaría General de Instituciones Penitenciarias y el Ilustre Colegio de Abogados de Málaga firmaron un convenio experimental, que pretende extenderse al resto de centros de la Administración General del Estado, para que los internos de los centros penitenciarios Málaga I (Alhaurín de la Torre, Málaga) y Málaga II (Archidona, Málaga) ${ }^{19}$ puedan comunicarse con sus abogados por videoconferencia.

Así pues, en primer lugar, tras estas primeras experiencias pilotos, habría que implantar este sistema en todo el territorio nacional, para después, a la luz de sus resultados, tratar de replicarla a nivel supranacional, de forma similar a lo que actualmente ya prevé la normativa europea e iberoamericana en otros ámbitos ${ }^{20}$.

19 Vid. el Diario de Sesiones del Congreso de los Diputados, Comisiones, Interior, Sesión n. 39, celebrada el jueves, 13 de diciembre de 2018, n. 691, 2018, p. 7, donde, en relación con el sistema de videoconferencia del centro penitenciario de Málaga II (Archidona, Málaga), se dice que "en este momento se está gestionando el correcto funcionamiento del sistema de videoconferencia, ya que este centro podría ser uno de los primeros en España en el que se celebren entrevistas entre los internos y sus abogados a través de videoconferencias".

20 A mayor abundamiento sobre este tema vid., por ejemplo, el art. 10 del Convenio relativo a la asistencia judicial en materia penal entre los Estados miembros de la Unión Europea, hecho en Bruselas el 29 de mayo de 2000; el art. 9 del Segundo Protocolo Adicional al Convenio europeo de asistencia judicial en materia penal, hecho en Estrasburgo el 8 de noviembre de 2001; el Convenio Iberoamericano sobre el uso de la videoconferencia en la Cooperación Internacional entre Sistemas de Justicia, hecho en Mar de Plata el 3 de diciembre de 2010, y su Protocolo adicional relacionado con los costos, régimen jurídico y remisión de solicitudes; o el más reciente art. 24 de la Directiva 2014/41/CE del Parlamento Europeo y del Consejo de 3 de abril de 2014 relativa a la orden europea de investigación en materia penal. Además, sobre este particular es aconsejable consultar JIMENO BULNES, Mar (Coord.). La cooperación judicial civil y penal en el ámbito de la Unión Europea: instrumentos procesales. Barcelona: Bosch, 2007; JIMENO BULNES, Mar (Dir.); MIGUEL BARRIO, Rodrigo (Coord.). Espacio judicial europeo y proceso penal. Madrid: Tecnos, 2018; y TIRADO ESTRADA, Jesús José. Videoconferencia, cooperación judicial internacional y debido proceso. Revista de la Secretaría del Tribunal Permanente de Revisión, Asunción, v. 5, n. 10, p. 153-173, 2017. http:// dx.doi.org/10.16890/rstpr.a5.n10.p153 


\section{Ventajas y DESVENTAJAS}

A nuestro juicio, dos son las principales ventajas de las comunicaciones por videoconferencia de los internos con el abogado defensor o con el abogado expresamente llamado en relación con asuntos penales.

En primer lugar, la de que contribuye a garantizar el ejercicio del derecho a la defensa y a la asistencia de letrado cuando el defendido se encuentra interno en un centro penitenciario, facilitando y mejorando la preparación de las actuaciones judiciales que se celebran durante la instrucción y el juicio oral.

En segundo lugar, la de que contribuye a ahorrar tiempo y dinero a los abogados, que tendrán mayores facilidades para trabajar y mayor flexibilidad para concertar reuniones sin depender de desplazamientos (que quedan muy reducidos con el uso de esta tecnología), haciéndolos más compatibles con el resto de su agenda. Esto es especialmente interesante en caso de que al interno, ya lo sea como preso preventivo o como penado, le haya sido reconocido el derecho a la asistencia jurídica gratuita y se le haya nombrado un abogado de oficio. En estos casos, la lejanía de las prisiones de los núcleos de población ${ }^{21}$ y la escasa remuneración que estos perciben por su trabajo provoca que, en ocasiones, los abogados desatiendan sus obligaciones y no acudan a los centros penitenciarios a visitar a sus defendidos.

Así pues, las comunicaciones por videoconferencia de los internos con el abogado defensor o con el abogado expresamente llamado en relación con asuntos penales serían complementarias, no sustitutivas, de las actualmente previstas en la LOGP y en el RP, es decir, de las comunicaciones orales, presenciales y telefónicas, y escritas ${ }^{22}$. De hecho,

21 MAPELLI CAFFARENA, Borja; BARAS GONZÁLEZ, Marcos. Sistemas de videoconferencia entre abogados y personas privadas de libertad. La Ley Penal: Revista de Derecho Penal, Procesal y Penitenciario, Madrid, n. 124, p. 3, 2017, hablan muy acertadamente de la "ruralización" en la ubicación de los centros penitenciarios.

22 Vid. el Acta de la Subcomisión de Derecho Penitenciario del Consejo General de la Abogacía Española (en adelante, CGAE) de 21 de octubre de 2005, p. 4, disponible en http://www.derechopenitenciario.com/comun/fichero. asp?id=2455 (consultado el 1 de julio de 2019), en la que con respecto a la 
cada uno de estos medios de comunicación tiene ventajas e inconvenientes según las circunstancias y el momento en el que se empleen. Así, habrá que diferenciar entre la primera o las primeras entrevistas entre el interno y su abogado, en las que la confianza entre ambos puede que aún no se haya fraguado (si no se conocían previamente), y las posteriores, pues en el primer caso las comunicaciones personales parecen más apropiadas a las restantes, incluida la videoconferencia, que se antoja más adecuada cuando

entrevista del abogado con su cliente en prisión a través de videoconferencia se dice que, "tras una amplia discusión sobre el particular, la Subcomisión entiende que la entrevista llevada a cabo a través de videoconferencia no debe sustituir a la personal, ya que se perdería perspectiva, sin embargo tampoco se puede renunciar a la utilización de los nuevos medios tecnológicos, por lo que en definitiva entiende que este tipo de entrevista debe ser complementaria a la llevada a cabo personalmente". Sin embargo, en el Acta de la Subcomisión de Derecho Penitenciario del GGAE de 11 de abril de 2014, pp. 4 y 5, disponible en http://www.derechopenitenciario.com/comun/fichero. asp?id=3991 (consultado el 1 de julio de 2019), en relación con el Proyecto Piloto de la Fundación del CGAE e Instituciones Penitenciarias sobre comunicaciones de abogados con sus clientes por videoconferencia, el presidente de la subcomisión, D. Carlos García Castaño, “entiende que es un sistema residual, no complementario, ya que valora la necesidad de ver a los presos y de visitar las prisiones, para fiscalizar, al menos visualmente, la actuación de la Administración Penitenciaria”, y, en definitiva, "no le ve mucho futuro". A mayor abundamiento sobre este tema vid. también el Acta de la Subcomisión de Derecho Penitenciario del CGAE de 26 de septiembre de 2014, disponible en http://www.derechopenitenciario.com/comun/fichero.asp?id=3993 (consultado el 1 de julio de 2019). En algunos centros penitenciarios de varios Estados y Condados de Estados Unidos (Arizona-Maricopa; Massachusetts-Bristol; Michigan-Calhoun-Kalamazoo; Texas-Travis; entre otros) ya se han sustituido las comunicaciones presenciales por comunicaciones por videoconferencia. De este modo, con carácter general, los familiares y amigos de los internos no pueden acudir al centro penitenciario a visitarlos, sino solo comunicarse gratuitamente desde unos quioscos con video que funcionan en el centro penitenciario, o descargar una aplicación que les permite hacer videoconferencias desde cualquier teléfono inteligente, con un coste que oscila entre los 8 y los 20 dólares, aproximadamente, para una llamada de unos 20-25 minutos (las comunicaciones con los abogados son gratuitas). Los ingresos obtenidos con este sistema se reparten entre la Administración y el proveedor del servicio. A mayor abundamiento sobre este tema en Texas vid. el documento titulado Video Visitation: how private companies push for visits by video and families pay the price, elaborado por Grassroots Leadership y the Texas Criminal Justice Coalition en octubre de 2014, disponible en http://grassrootsleadership.org/sites/default/files/uploads/Video\%20 Visitation\%20\%28web\%29.pdf (consultado el 1 de julio de 2019). 
la relación entre ambos es más estrecha. Asimismo, habrá que diferenciar entre si el motivo de la comunicación es para cuestiones relevantes, como, por ejemplo, la preparación de la declaración de investigado en la instrucción o el juicio oral, o para cuestiones de trámite, pues, de nuevo, en el primer caso las comunicaciones personales parecen más apropiadas que las restantes, incluida la videoconferencia, que se antoja más adecuada cuando la comunicación tiene por objeto cuestiones de trámite. Del mismo modo, habrá que diferenciar si la comunicación es urgente o no, pues en el primer caso las comunicaciones telefónicas y por videoconferencia parecen más apropiadas a las comunicaciones orales (presenciales) y escritas.

No obstante, las comunicaciones por videoconferencia de los internos con el abogado defensor o con el abogado expresamente llamado en relación con asuntos penales también pueden tener una parte negativa, como, por ejemplo, la de que la popularización de este tipo de comunicaciones, dadas las ventajas a las que hemos hecho alusión anteriormente, desplace las comunicaciones orales (presenciales), con la consiguiente pérdida de "contacto físico" entre el interno y su abogado. Otro posible inconveniente del uso de esta tecnología para este fin es la mayor facilidad (al menos, aparentemente) de que este tipo de comunicaciones puedan ser intervenidas u oídas por alguien ajeno a ellas, con el consiguiente aumento de la desconfianza de los intervinientes en la misma (principalmente, del interno) de revelar datos sensibles, pero que pueden ser esenciales para la defensa.

\section{Desarrollo}

Para ver como podría ser el desarrollo de las comunicaciones por videoconferencia de los internos con el abogado defensor o con el abogado expresamente llamado en relación con asuntos penales, en primer lugar, hemos de preguntarnos cuál es la naturaleza de las comunicaciones por videoconferencia, es decir, si estas se han de ajustar a lo dispuesto en relación con las comunicaciones orales (presenciales) o con las comunicaciones telefónicas, ya que según sea una u otra, la regulación de las mismas deberá ser más próxima a lo dispuesto en los arts. 51.1, 
2, 3 y 5 LOGP y 42 a 45 y 48 y 49 RP, en el primero de los casos, o en los arts. 51.4 y $47 \mathrm{RP}$, en el segundo.

A nuestro juicio, la naturaleza de las comunicaciones por videoconferencia es la misma que la de las comunicaciones telefónicas, por lo que hemos de partir de lo dispuesto en los arts. 51.4 LOGP y 47 RP. Sin embargo, como veremos a continuación, las primeras experiencias de comunicaciones por videoconferencia de los internos con el abogado defensor o con el abogado expresamente llamado en relación con asuntos penales no parecen partir de la regulación de este tipo de comunicaciones, sino de lo dispuesto para las comunicaciones orales (presenciales).

\subsection{Solicitud}

En primer lugar, hemos de preguntarnos cuáles pueden ser las razones que justifiquen el uso de esta tecnología en el ámbito penitenciario. En el ámbito judicial, las razones que justifican el uso de esta tecnología son razones de utilidad, seguridad o de orden público, así como en aquellos supuestos en que la comparecencia de quien haya de intervenir en cualquier tipo de procedimiento penal como investigado o encausado, testigo, perito, o en otra condición resulte particularmente gravosa o perjudicial, y, especialmente, cuando se trate de un menor (arts. 325 y 731 bis LECrim). Sin embargo, en el ámbito penitenciario, las razones que, en nuestra opinión, justifican el uso de esta tecnología son, además de evidentes razones de utilidad, razones de seguridad, de interés del tratamiento y del buen orden del establecimiento (arts. 51.1 LOGP y 41.2 RP). Estas razones constituyen también los límites del uso de la videoconferencia en el ámbito penitenciario, por lo que cabe preguntarse si el uso de esa tecnología para este fin solo debe tener aplicación cuando el interno lo está en un centro penitenciario fuera del ámbito territorial de su abogado, como sostienen algunos ${ }^{23}$, o puede tenerlo también con independencia

23 A mayor abundamiento vid. el Acta de la Subcomisión de Derecho Penitenciario del GGAE de 11 de abril de 2014, pp. 4 y 5, disponible en http://www. derechopenitenciario.com/comun/fichero.asp?id=3991 (consultado el 1 de julio de 2019), en la que, en relación con el Proyecto Piloto de la Fundación del CGAE e Instituciones Penitenciarias sobre comunicaciones de abogados con sus clientes por videoconferencia, el presidente de la subcomisión, D. 
de esta circunstancia. En nuestra opinión, el hecho de que el interno se encuentre en un centro penitenciario más o menos cercano al despacho de su abogado no debe ser óbice para que ambos puedan hacer uso de este medio de comunicación.

Por otro lado, hemos de plantearnos quién ha de acordar o quién puede solicitar que las comunicaciones de los internos con el abogado defensor o con el abogado expresamente llamado en relación con asuntos penales se realicen a través de videoconferencia, si ha de ser el tribunal, de oficio o a instancia de parte; estas últimas por su propia voluntad; o la Administración Penitenciaria. En principio, la intervención judicial no es necesaria salvo supuestos excepcionales, como sucede, por ejemplo, en los supuestos de terrorismo o de internos pertenecientes a bandas o grupos armados, en los que el volante para las comunicaciones orales (presenciales) debe ser expedido por la autoridad judicial que conozca de las correspondientes causas, sin perjuicio de lo dispuesto en el art. 520 LECrim (art. 48.1.2 ${ }^{a}$ RP); ni la de la Administración Penitenciaria, por lo que la solicitud del uso de este sistema queda en manos de los abogados ${ }^{24}$.

La solicitud de la comunicación por videoconferencia debe hacerse con una cierta antelación para que los funcionarios puedan llevar al interno al locutorio donde esta se desarrolle y para que puedan organizar las diversas solicitudes de comunicaciones de los internos. No hay un plazo

Carlos García Castaño, "entiende que debemos ser restrictivos en su aplicación", por lo que "se plantea por que no solicitar que ambos proyectos, Madrid y Málaga, se hagan para videoconferencias con presos que estén en prisiones fuera de su ámbito territorial, que es lo que tendría más sentido, y no con las prisiones más cercanas como se pretende hacer".

El apartado primero del Conveni de colllaboració entre el Departament de Justícia i el Consell dels Il-lustres Col-legis d'Advocats de Catalunya, per a la implantació del programa de videocomunicacions entre les persones internes en centres penitenciaris i centres educatius de justícia juvenil i els seus advocats defensors, de 23 de març de 2017, p. 3, parece circunscribir el uso de la videoconferencia unicamente a los "que siguin col-legiats dels il-lustres collegis d'advocats de Catalunya", descartando a los que estén colegiados en otros Colegios de Abogados de España o de otros países. Exactamente lo mismo se prevé en la experiencia piloto puesta en marcha por la Secretaría General de Instituciones Penitenciarias y el Ilustre Colegio de Abogados de Málaga en los centros penitenciarios Málaga I (Alhaurín de la Torre, Málaga) y Málaga II (Archidona, Málaga). 
oficial, pero en los proyectos pilotos puestos en marcha actualmente este plazo oscila entre las 48 horas $^{25}$ y los cinco días ${ }^{26}$.

Actualmente, en relación con las comunicaciones telefónicas, se establece que, salvo casos excepcionales, libremente apreciados por el Director del establecimiento, no se permitirán llamadas desde el exterior a los internos (art. 47.5 RP). En cierto modo, las comunicaciones por videoconferencia podrían ser una excepción a este régimen general cuando fuere el abogado quien llamara por videoconferencia al interno, lo que, no obstante, es totalmente intrascendente en la práctica, ya que, como veremos a continuación, debe haber un concierto previo entre el abogado y el centro penitenciario para que dicha comunicación sea posible.

\subsection{INTERVINIENTES}

Los intervinientes en las comunicaciones por videoconferencia de los internos con el abogado defensor o con el abogado expresamente llamado en relación con asuntos penales pueden ser:

- El interno o los internos, toda vez que el uso de la videoconferencia en los centros penitenciarios como forma de garantizar el ejercicio del derecho a la defensa y a la asistencia de letrado en el proceso penal debe ser posible tanto para las comunicaciones entre internos del mismo o de distintos centros penitenciarios, como para las comunicaciones conjuntas de estos y sus abogados.

25 Vid. el apartado octavo del Conveni de col-laboració entre el Departament de Justícia i el Consell dels Il-lustres Col-legis d'Advocats de Catalunya, per a la implantació del programa de videocomunicacions entre les persones internes en centres penitenciaris i centres educatius de justícia juvenil i els seus advocats defensors, de 23 de març de 2017, p. 6; y MAPELLI CAFFARENA, Borja; BARAS GONZÁLEZ, Marcos. Sistemas de videoconferencia..., cit., p. 4, que estiman "que este plazo, con carácter general, puede ser de 48 horas".

26 MAPELLI CAFFARENA, Borja; BARAS GONZÁLEZ, Marcos. Sistemas de videoconferencia..., cit., p. 6, nota 4 , dicen que en el caso de la experiencia piloto que actualmente se desarrolla en Cataluña "la petición se formula con una antelación mínima de cinco días naturales a la fecha en que quieran comunicarse con su cliente". 
Y es que, en efecto, hemos de pensar en la posibilidad del uso de la videoconferencia para las comunicaciones entre internos del mismo o de distintos centros penitenciarios para el ejercicio del derecho de defensa.

Las comunicaciones entre internos del mismo centro penitenciario no aparecen expresamente reguladas ni en la LOGP ni en el RP. En cambio, no ocurre lo mismo con las comunicaciones entre internos de distintos centros penitenciarios, los cuales pueden hacer uso de comunicaciones escritas (art. 46.7 ${ }^{\mathrm{a}} \mathrm{RP}$ ) y telefónicas (art. 47.6 RP). Sin embargo, no se prevé expresamente la posibilidad de comunicaciones orales (presenciales, arts. 42 a $45 \mathrm{RP}$ ), aunque quizás ello podría autorizarse si se considerase que los internos que desean comunicar oralmente entre sí son amigos (arts. 51.1 LOGP y 41.1 RP) o allegados (arts. 53 LOGP y 45.1, 3 y 5 RP) ${ }^{27}$.

En principio, nada impide que estas comunicaciones entre internos de distintos establecimientos puedan ser entre dos (un interno en cada uno de los centros penitenciarios) o más (uno o varios internos en un centro penitenciario y uno o varios en el otro), e, incluso, porque la tecnología actual así lo permite, entre varios internos situados en tres o más establecimientos. Y es que no hemos de olvidar que las salas de videoconferencia deben tener cabida para un mínimo de cinco internos y un máximo de diez, en función de las disponibilidades de cada uno de los centros ${ }^{28}$, por lo que esta circunstancia no es ningún impedimento.

Sin embargo, el primer problema que nos encontramos aquí es que, aunque se prevén las comunicaciones telefónicas entre internos de distintos establecimientos (art. 47.6 RP), estas comunicaciones solo deben autorizarse entre internos que acrediten relación de afectividad o parentesco, lo que excluye, en la mayoría de los casos, que el motivo

27 A mayor abundamiento vid. la Instrucción 4/2005, de 16 de mayo, de la Dirección General de Instituciones Penitenciarias, que, aunque no es especialmente restrictiva con las comunicaciones orales entre internos del mismo centro (p. 7), sí lo es con las de distintos centros (p. 8) cuando señala que “en ningún caso se autorizarán si los Centros están en distinta localidad”. Lo mismo sucede con las comunicaciones telefónicas entre internos de distintos centros (p. 9), que "sólo se autorizarán entre internos que acrediten relación de afectividad o parentesco".

28 Vid. la Instrucción 2/2007, de 30 de enero, de la Dirección General de Instituciones Penitenciarias, p. 2. 
de la misma sea el ejercicio del derecho a la defensa y a la asistencia de letrado ${ }^{29}$, aunque en algún caso puntual ello sí haya sido autorizado por este motivo ${ }^{30}$.

Por tanto, en caso de que la regulación de las comunicaciones por videoconferencia se asimilase en el futuro a la actualmente vigente de las comunicaciones telefónicas, ello impediría el uso de la videoconferencia para las comunicaciones entre internos de distintos establecimientos para el ejercicio de estos derechos.

Además, entendemos que estas, al igual que sucede actualmente con las comunicaciones telefónicas, podrían ser intervenidas mediante resolución motivada del Director en la forma y con los efectos previstos en el art. 46.7 $\mathrm{RP}$ (art. 47.6 RP), por lo que difícilmente pudieran destinarse a este fin ante el temor de los internos de que lo que se dijeran pudiera ser escuchado por personas ajenas a la comunicación.

Otra posibilidad, que actualmente no contempla ni siquiera el RP en relación con las comunicaciones telefónicas, consiste en que esto se desarrolle con la intervención también de los abogados de estos internos o, al menos, de algunos de ellos, con objeto de preparar la defensa, es decir, en el uso de la videoconferencia para las comunicaciones entre internos de distintos establecimientos y sus abogados, estando estos en el centro o los centros penitenciarios o en otros lugares.

Lógicamente, en estos casos, estas comunicaciones no podrían ser intervenidas mediante resolución motivada del Director en la forma y con los efectos previstos en el art. $46.7^{\mathrm{a}} \mathrm{RP}$, sino que se acogerían al

29 Vid. la Instrucción 4/2005, de 16 de mayo, de la Dirección General de Instituciones Penitenciarias, p. 9.

30 En efecto, según noticias aparecidas en los medios de comunicación, en relación con líderes del "procés" que se encontraban internos en distintos centros penitenciarios de Cataluña, la dirección del centro penitenciario de Lledoners (San Juan de Torruella, Barcelona), donde estaban internos D. Oriol Junqueras i Vies, D. Raül Romeva i Rueda, D. Jordi Sànchez i Picanyol y D. Jordi Cuixart i Navarro, y del centro penitenciario Puig de les Basses (Figueras, Gerona), donde estaban internas Dña. Dolors Bassa i Coll y Dña. Maria Carme Forcadell i Lluís, autorizó (a nuestro juicio indebidamente, ya que, como estamos viendo, no está previsto su uso para este fin) que estos internos pudieran comunicarse entre ellos por medio de esta vía. 
régimen general de la intervención de las comunicaciones de los internos con sus abogados defensores del art. $48.3 \mathrm{RP}^{31}$.

- El abogado o los abogados, toda vez que, como acabamos de ver, debería ser posible que en la comunicación por videoconferencia pudieran estar presente el abogado o los abogados del interno o de los internos y el abogado o los abogados de otro u otros internos por la misma causa. Asimismo, también debería ser posible que estuvieran presentes estudiantes de Grado o Máster que fuesen becarios o pasantes de alguno de estos abogados.

- El funcionario o los funcionarios, toda vez que la celebración de cualquier videoconferencia debe estar controlada por uno o varios funcionarios, en función del número y características de los internos desplazados. Si bien estos, por razones de confidencialidad no pueden intervenir directamente en la comunicación, como veremos a continuación, el funcionario o los funcionarios deberán comprobar no solo la identidad del interno, sino también la del abogado ${ }^{32} \mathrm{y}$, en su caso, la de otros intervinientes.

- Otros intervinientes. Actualmente, mientras que en la experiencia piloto puesta en marcha por la Secretaría General de Instituciones Penitenciarias y el Ilustre Colegio de Abogados de Málaga se prevé que en las comunicaciones por videoconferencia de los internos con el abogado defensor o con el abogado expresamente llamado en relación con asuntos penales no puedan participar terceras personas, salvo que sea estrictamente necesario (como un intérprete), ya que, según se dice, este tipo de comunicaciones están sujetas al mismo reglamento que rige las entrevistas personales, algunos autores sostienen que el abogado también ha de poder estar acompañado por las personas que este, en su

31 A mayor abundamiento sobre este tema vid. los arts. 118.4 LECrim y 51.2 LOGP; y RODRÍGUEZ ÁLVAREZ, Ana; GARCÍA MONTEAGUDO, Alexandre. La intervención de las comunicaciones telefónicas y telemáticas entre el abogado y el investigado. En: BUENO DE MATA, Federico (Dir./Coord.). FODERTICS 6.0: los nuevos retos del derecho ante la era digital. Granada: Comares, 2017. p. 183-194.

32 Aunque, como veremos más adelante, en las comunicaciones por videoconferencia de los internos con el abogado defensor o con el abogado expresamente llamado en relación con asuntos penales esto también puede corresponderle al Colegio de Abogados con respecto a sus colegiados. 
caso, autorizare ${ }^{33}$. Como ya hemos dicho anteriormente, parece lógico que el abogado pudiera estar acompañado por otro abogado, de su despacho o no, por un pasante, por un intérprete, o por un perito. En cambio, no parece que deba ser posible que otras personas ajenas a la defensa, como, por ejemplo, familiares del interno, deban poder estar presentes, de forma que la comunicación por videoconferencia con el abogado se utilizara indebidamente para hacer otro tipo de comunicación. Bien es cierto que, en la actualidad, esto es perfectamente posible que suceda en las comunicaciones telefónicas con el abogado, pues no hay ningún sistema que garantice que en el despacho del abogado o donde este se encuentre no esté, junto a él, un familiar del interno o cualquier otra persona que hable con él. A pesar de ello, entendemos que al tiempo de la solicitud de cita de la comunicación por videoconferencia con el abogado, lo que, a nuestro juicio, dicho sea de paso, debería hacerse por medio de las nuevas tecnologías (app, página web, o similar), este debería especificar si a la videoconferencia acudirá solo o acompañado, y, en este caso, por quién, especificando sus datos personales y el motivo de su presencia, de forma que esto se tenga en cuenta a la hora de autorizar o no la comunicación y pueda ser controlado posteriormente, el día en que se lleve a cabo la misma, por el funcionario o los funcionarios.

\subsection{IDENTIFICACIÓN DE LOS INTERVINIENTES}

Con respecto a la identificación de los intervinientes, habrá que distinguir entre la identificación de los internos y la de los abogados y, en su caso, terceras personas.

La identificación de los internos se hará a través del Documento de Identificación Interior, cacheo de los mismos y revisión con la raqueta o arco detector, debiendo verificarse previamente, además, la existencia de posibles incompatibilidades entre los internos participantes, si fueran $\operatorname{varios}^{34}$.

33 Vid. MAPELLI CAFFARENA, Borja; BARAS GONZÁLEZ, Marcos. Sistemas de videoconferencia..., cit, p. 4.

34 Vid. la Instrucción 2/2007, de 30 de enero, de la Dirección General de Instituciones Penitenciarias, p. 6. 
Durante la celebración de la videoconferencia los internos deben poder portar aquellos objetos necesarios para el buen fin de la comunicación con sus abogados y deben poder exhibir documentos $\mathrm{u}$ objetos sin que sea necesario que por razones debidamente justificadas la Dirección del centro lo haya autorizado ${ }^{35}$. Es decir, la regla general ha de ser que los internos puedan portar y exhibir estos documentos $\mathrm{u}$ objetos, salvo que por razones debidamente justificadas ${ }^{36}$ la Dirección del centro lo haya denegado.

Por otro lado, para la celebración de las comunicaciones de los internos con sus abogados defensores se debe identificar al comunicante mediante la presentación del documento oficial que le acredite como abogado en ejercicio (art. 48.1.1 ${ }^{\mathrm{a}} \mathrm{RP}$ ), es decir, mediante su carné de colegiado en el colegio de abogados de que se trate, que se le podrá requerir por el funcionario de Instituciones Penitenciarias encargado de la videoconferencia.

Además, el comunicante habrá de presentar un volante de su respectivo Colegio, en el que conste expresamente su condición de defensor del interno en las causas que se siguieran contra el mismo o como consecuencia de las cuales estuviera cumpliendo condena. En los supuestos de terrorismo o de internos pertenecientes a bandas o grupos armados, como ya hemos dicho anteriormente, el volante deberá ser expedido por la autoridad judicial que conozca de las correspondientes causas, sin perjuicio de lo dispuesto en el art. 520 LECrim (art. 48.1.2 ${ }^{\mathrm{a}} \mathrm{RP}$ ).

A diferencia de lo que se prevé para los internos (cacheo de los mismos y revisión con la raqueta o arco detector) y para los abogados en las comunicaciones orales (presenciales), en las comunicaciones por videoconferencia esto carece de sentido para estos últimos, toda vez que los mismos se encuentran en todo momento fuera del centro penitenciario. No obstante, en la experiencia piloto puesta en marcha por la Secretaría General de Instituciones Penitenciarias y el Ilustre Colegio de Abogados

35 Al contrario de lo que actualmente dispone la Instrucción 2/2007, de 30 de enero, de la Dirección General de Instituciones Penitenciarias, p. 6.

36 Como, por ejemplo, razones de seguridad, de interés del tratamiento y del buen orden del establecimiento (arts. 51.1 LOGP y 41.2 RP). 
de Málaga se prevé que los abogados deban demostrar que no van a utilizar dispositivos que permitan la grabación ${ }^{37}$ o la llamada de otras personas durante las sesiones de videoconferencias ${ }^{38}$, es decir, que el abogado no podrá llevar su teléfono móvil o cualquier otro dispositivo tecnológico que le permita comunicarse con terceras personas, lo que plantea la duda de cómo habrá de llevarse esto a cabo, teniendo en cuenta que el abogado, al estar fuera del centro penitenciario (en las dependencias del Colegio de Abogados o en otro sitio), no puede ser sometido a revisión con raqueta o arco detector ni cacheado por los funcionarios, como sí sucede en las comunicaciones orales (presenciales).

Así pues, la identificación de los abogados puede ser doble: virtual, por los funcionarios de prisiones desde el centro penitenciario a través del sistema de videoconferencia, y presencial, por los trabajadores del Colegio de Abogados en el lugar desde donde esta se desarrolle ${ }^{39}$, que normalmente, como veremos a continuación, será el Colegio de Abogados.

37 MAPELLI CAFFARENA, Borja; BARAS GONZÁLEZ, Marcos. Sistemas de videoconferencia..., cit., p. 3, parecen dejar abierta la puerta a que las conversaciones por videoconferencia puedan ser grabadas cuando dicen que con ellas se pretende "facilitar en determinadas circunstancias la incorporación a un soporte informático de las entrevistas con su cliente con el objetivo de que el Abogado pueda hacer uso del mismo en el desarrollo de la defensa - presentarlo como prueba, transferirlo a otros colegas, archivo, etc. -".

38 Como ya hemos dicho anteriormente, esto es perfectamente posible que suceda en las comunicaciones telefónicas con el abogado, pues no hay ningún sistema que garantice que estos no están grabando la llamada o que en el despacho del abogado o donde este se encuentre no esté, junto a él, un familiar del interno o cualquier otra persona que hable con él.

39 Por esta segunda opción es por la que se ha optado en la experiencia piloto que actualmente se desarrolla en Cataluña, donde el apartado noveno del Conveni de col-laboració entre el Departament de Justícia i el Consell dels Il-lustres Col-legis d'Advocats de Catalunya, per a la implantació del programa de videocomunicacions entre les persones internes en centres penitenciaris i centres educatius de justícia juvenil i els seus advocats defensors, de 23 de març de 2017, p. 7, dice que "arribat el moment en què s'hagi d'establir la comunicació, l'illlustre col-legi haurà de confirmar que la persona que es presenta com a advocat és efectivament la persona designada en el moment de fer la petició i no permetrà que se celebri si es presenta una altra persona en el seu lloc". 


\subsection{LUGAR}

Con respecto al lugar de las comunicaciones por videoconferencia de los internos con el abogado defensor o con el abogado expresamente llamado en relación con asuntos penales hemos de advertir que realmente hemos de hablar más bien de lugares, ya que estas se desarrollan al mismo tiempo desde dos o más sitios distintos. Así pues, hemos de distinguir entre el lugar donde se encuentre el interno, que, en todo caso, será dentro del centro penitenciario, y el lugar donde se encuentre el abogado, que, en todo caso, será fuera del centro penitenciario, toda vez que, en caso contrario, no tendría sentido hacer uso de este medio de comunicación.

En cuanto al lugar donde se encuentre el interno, estas comunicaciones deben celebrarse en locutorios especiales, en los que quede asegurado que el control del funcionario encargado del servicio sea solamente visual (arts. 47.4 y $48.1 .3^{\mathrm{a}} \mathrm{RP}$ ).

Aunque las salas de videoconferencias deben disponer, además de la zona para internos, de una zona contigua, para la estancia de funcionarios, separadas, ambas, por una mampara de visión unidireccional, para el adecuado control visual ${ }^{40}$, el problema es que de esta forma realmente pueda garantizarse la confidencialidad de las comunicaciones entre el interno y su abogado.

Por ello, aunque se prevé41 que su uso solo se dé cuando no sea posible la instalación de mampara de cristal de visión unidireccional, a nuestro juicio, sería más conveniente que el control visual se hiciera, en su caso, mediante una cámara de seguridad que careciese de micrófonos que le permitiesen captar el sonido, lo que permitiría alejar a los funcionarios del lugar donde se estuviese desarrollando la comunicación, y, con ello, se despejaría el posible temor de los comunicantes de que la comunicación estuviese siendo oída por los funcionarios ${ }^{42}$. Lógicamente, este sistema

40 Vid. la Instrucción 2/2007, de 30 de enero, de la Dirección General de Instituciones Penitenciarias, p. 3.

41 Ibídem, pp. 3 y 5, donde se dice que "el control se realizará desde la cabina de seguridad y a través de la mampara de cristal unidireccional o, en su defecto, por circuito cerrado de TV".

42 Tal como actualmente se prevé en el apartado sexto del Conveni de col-laboració entre el Departament de Justícia i el Consell dels Il·lustres Col·legis 
debería implicar a su vez dos cosas: la primera es que la cámara de seguridad debería estar situada de tal forma que impidiese que se pudiera leer los labios de los comunicantes y los documentos de que pudieran hacer uso, y, en segundo lugar, que en el locutorio debería haber un cartel informativo en el que se advirtiese de que no se graba el vídeo ni se almacena lo grabado, sino que el sistema de videovigilancia solo permite la visión en directo de la imagen, pero no del audio.

La sala de la videoconferencia también debe estar dotada de un sistema de intercomunicación entre la sala y la cabina de seguridad, aunque dicho sistema debe impedir que el funcionario pueda oír lo que en ella se dice.

El funcionario podrá entrar con el interno en el locutorio donde se halle el equipo de videoconferencia para activar el mismo y comprobar que la comunicación es posible, pero deberá ausentarse antes de que verdaderamente comience la comunicación entre el interno y su abogado para respetar la confidencialidad de la misma. No obstante, deberá controlar visualmente su desarrollo. Actualmente, esto plantea el problema del aislamiento acústico de los locutorios en los que se desarrollan la videoconferencia. Estos no suelen ser habitáculos totalmente aislados acústicamente, lo que permite que, en ocasiones, quien está fuera pueda oír lo que se dice en su interior. Hemos de tener en cuenta que el sistema actual de videoconferencia, en muchos casos, hace que lo que el interno oye o lo que dice esté a un volumen muy elevado, por lo que puede filtrarse al exterior. Este no es un tema baladí, como pudiera parecer, sino que, muy al contrario, puede suponer una merma real al efectivo ejercicio del derecho a la defensa ${ }^{43}$.

d'Advocats de Catalunya, per a la implantació del programa de videocomunicacions entre les persones internes en centres penitenciaris i centres educatius de justícia juvenil i els seus advocats defensors, de 23 de març de 2017, p. 5, que, al respecto dice que "per tal de garantir en tot moment la confidencialitat de les comunicacions advocat-persona interna, aquests locutoris disposaran d'un sistema de videovigilància amb senyal únicament visual".

43 A mayor abundamiento vid. la Sentencia del Tribunal Europeo de Derechos Humanos de 13 de mayo de 2007 (caso Castravet contra Moldavia), según la cual, aplicando analógicamente lo que señalaba la defensa del Sr. Castravet con respecto al uso de la mampara en los locutorios al ámbito que ahora nos ocupa, la videoconferencia crea una barrera para la confidencialidad, ya que 
En cuanto al lugar donde se encuentre el abogado, este puede ser el despacho del abogado o cualquier otro sitio donde este se encuentre, el Colegio de Abogados, un juzgado o tribunal u otras dependencias públicas o privadas.

MAPELLI CAFFARENA y BARAS GONZÁLEZ ${ }^{44}$ entienden que "en un primer momento y hasta la consolidación del sistema las videoconferencias se realizarán desde las sedes de los Colegios de Abogados, pero una vez consolidado el procedimiento, [...], se podrá realizar directamente desde los despachos profesionales o, incluso desde un dispositivo móvil del Abogado siempre cumpliendo las garantías de privacidad y protección de datos necesarias". Y es que, en efecto, los dispositivos tecnológicos actuales permiten, al igual que sucede con las comunicaciones telefónicas, que los abogados puedan comunicarse por videoconferencia desde cualquier lugar mediante su teléfono móvil o su ordenador.

Sin embargo, en la experiencia piloto puesta en marcha por la Secretaría General de Instituciones Penitenciarias y el Ilustre Colegio de Abogados de Málaga se prevé que los abogados solo pueden comunicarse con sus clientes a través de unos puestos específicos ubicados en la sede del Colegio o en una de sus nueve delegaciones, nunca desde un dispositivo propio o desde el despacho del abogado, un juzgado o tribunal u otras dependencias públicas o privadas.

A nuestro juicio, no debería haber inconveniente en que estas comunicaciones se celebrasen desde cualquiera de estos lugares, especialmente desde el despacho del abogado, desde el que, como ya hemos dicho anteriormente, ya es posible mantener comunicaciones telefónicas incluso, hipotéticamente, con una o varias personas (a través del sistema

tanto el preso como su abogado deben alzar la voz para poder oírse, gritos que habrían facilitado la intercepción o grabación de su conversación y que, en cualquier caso, sus gritos generaban el riesgo de que su discusión fuese escuchada por los guardas o a través de la puerta. Este riesgo de escucha es suficiente, pues, como ha dicho el Tribunal Europeo de Derechos Humanos en esta sentencia, "tal creencia inhibiría inevitablemente la libertad de discusión entre el abogado y el cliente".

44 Vid. MAPELLI CAFFARENA, Borja; BARAS GONZÁLEZ, Marcos. Sistemas de videoconferencia..., cit., p. 4. 
de manos libres) ajenas al despacho. Pudiera pensarse que el motivo de que ello no se permita se debe a razones de seguridad, ante la posibilidad de que las comunicaciones efectuadas desde estos lugares puedan hacerse a través de canales poco seguros que permitan su interceptación o ante el temor de que se usen para comunicarse con familiares y otras personas, pero, como venimos diciendo, ambos riesgos están también presentes en las comunicaciones telefónicas, que, sin embargo, están plenamente admitidas y no generan esta desconfianza.

\subsection{TIEMPO}

También hemos de analizar el tiempo (periocidad y duración) en el que dicha comunicación por videoconferencia es posible.

La periodicidad y duración de las comunicaciones por videoconferencia de los internos con el abogado defensor o con el abogado expresamente llamado en relación con asuntos penales dependerá, entre otras cuestiones, de los recursos materiales ${ }^{45} \mathrm{y}$ humanos disponibles $\mathrm{y}$ del número de solicitudes de abogados e internos que quieran hacer uso de este medio de comunicación.

En el caso de las comunicaciones orales (presenciales) con abogados, respecto al tiempo de la visita, hemos de decir que las mismas, a diferencia de lo que sucede con las que se llevan a cabo con sus familiares, amigos y representantes acreditados de organismos e instituciones de cooperación penitenciaria, no están sujetas a plazo.

Sin embargo, en el caso de las comunicaciones telefónicas, estas, siempre que las circunstancias del establecimiento lo permitan, deben efectuarse con una frecuencia máxima de cinco llamadas por semana y no deben tener una duración superior a cinco minutos (art. 47.4 RP) ${ }^{46}$,

45 Así, por ejemplo, en el Centre Penitenciari Brians 1 (San Esteban de Sasroviras, Barcelona) se han instalado ocho equipos con capacidad para 16.000 comunicaciones anuales.

46 Aunque actualmente, con carácter general, se permiten hasta diez llamadas por semana de hasta ocho minutos cada una, al igual que ya sucedía en los centros penitenciarios de la comunidad autónoma de Cataluña. 
límite dentro del cual deben entenderse incluidas las comunicaciones con el abogado ${ }^{47}$.

Por ello cabe preguntarse cuál debe ser la duración de las comunicaciones por videoconferencia de los internos con el abogado defensor o con el abogado expresamente llamado en relación con asuntos penales. Si lo que se quiere es evitar desplazamientos al centro penitenciario, no parece lógico que, en este caso, la comunicación pueda tener una duración tan restringida como la que actualmente tienen las comunicaciones telefónicas, siendo más adecuado, a nuestro juicio, que esta comunicación se acerque, lo más posible, a la duración "sin límites" que tienen actualmente las comunicaciones orales (presenciales). Con carácter ordinario, se podría fijar una duración de 30 minutos ${ }^{48}$, con

47 Vid. el razonamiento jurídico segundo del Auto del Juzgado Central de Vigilancia Penitenciaria de 6 de junio de 2014. En el mismo sentido se pronuncia el Auto del Juzgado de Vigilancia Penitenciaria de Ciudad Real de 15 de abril de 2002, donde se analiza un supuesto en el que "el interno formula queja contra la decisión del Centro por contabilizar la llamada telefónica del interno a su abogado dentro de las dos llamadas semanales a su familia”. En efecto, "en el Centro se autorizan solo dos llamadas telefónicas semanales, incluidas las del abogado, ya que no excepciona éstas del resto de llamadas", y se recuerda que el art. $47 \mathrm{RP}$ "no excepciona las llamadas telefónicas con los abogados del resto de las llamadas, por lo que el límite, genérico de cinco llamadas telefónicas, debe entenderse del total de llamadas telefónicas”. Esta misma línea se sigue en el Auto de la Audiencia Provincial de Ciudad Real de 2 de junio de 2003, según el cual, "los internos [...] tendrán derecho a comunicar telefónicamente con sus familiares cinco veces a la semana en los términos del artículo 47.4 del Reglamento Penitenciario, de cuyo cupo máximo se deducirán, en su caso, las llamadas telefónicas que el interno realice a su abogado defensor o a otras personas". No obstante, "el Gobierno va a llevar a cabo una modificación en la aplicación informática para que el sistema no contabilice las llamadas del interno al abogado en el cupo de llamadas autorizadas", tal como consta en la respuesta del Gobierno de 11 de julio de 2018 a la pregunta escrita que el senador D. Jon Iñarritu García, Senador del Euskal Herria Bildu (EH Bildu) designado por el Parlamento Vasco, del Grupo Parlamentario Mixto (GPMX), formuló al Gobierno sobre este particular el 3 de mayo de 2018. A mayor abundamiento vid. http://www.senado.es/web/actividadparlamentaria/iniciativas/detalleiniciativa/textosexpedientes/index. html?legis=12\&id1=684\&id2=044687 (consultado el 1 de julio de 2019).

48 Aunque MAPELLI CAFFARENA, Borja; BARAS GONZÁLEZ, Marcos. Sistemas de videoconferencia..., cit., p. 6, nota 4, dicen que en la experiencia piloto que actualmente se desarrolla en Cataluña, los tramos horarios son "de media hora para cada visita", como consta en el apartado séptimo del 
independencia de que, según la demanda, esta pudiera prolongarse como si de una comunicación oral (presencial) se tratase.

Del mismo modo, en la experiencia piloto puesta en marcha por la Secretaría General de Instituciones Penitenciarias y el Ilustre Colegio de Abogados de Málaga únicamente se prevé que las entrevistas con los abogados puedan celebrarse, de momento, de lunes a jueves, en horario de 17:30 a 19:30 h. y con un intervalo de quince minutos que permita el relevo de internos en la sala de videoconferencia. El hecho de que las comunicaciones por videoconferencia de los internos con el abogado defensor o con el abogado expresamente llamado en relación con asuntos penales solo sean por las tardes y en un horario concreto restringe lo dispuesto en el régimen de comunicaciones orales (presenciales, no en el caso de las telefónicas, como hemos visto), y, aunque el tiempo de la visita tan solo se puede restringir por razones de seguridad, de interés del tratamiento y del buen orden del establecimiento (arts. 51.1 LOGP y 41.2 RP), entendemos que ello está justificado, al menos en estos momentos iniciales en los que de lo que se trata es de poner en marcha el sistema ${ }^{49}$. Aún así, uno de los aspectos negativos de que la comunicación

Conveni de col-laboració entre el Departament de Justícia i el Consell dels Il-lustres Col-legis d'Advocats de Catalunya, per a la implantació del programa de videocomunicacions entre les persones internes en centres penitenciaris i centres educatius de justícia juvenil i els seus advocats defensors, de 23 de març de 2017, pp. 5 y 6, "la durada màxima de les videocomunicacions serà de 60 minuts, amb caràcter general. En el moment de fer la reserva a l'agenda, el col-legi haurà de concretar quina serà la durada de la comunicació $(10,15$, 20, 30 minuts, etc., fins a un màxim de $60 \mathrm{amb}$ caràcter general). Si per causes degudament justificades es considera que la videoconferència ha de durar més d'aquest temps, en el moment de fer la reserva a l'agenda corresponent es podrà reservar per un temps superior, tot ajustant-se a les necessitats reals i amb l'objectiu de fer un ús eficient dels espais". A mayor abundamiento vid. también la Resolució JUS/524/2018, de 19 de març, per la qual es determinen els horaris d'admissions voluntàries en els centres penitenciaris de Catalunya i de comunicacions presencials de les persones internes amb advocats i altres professionals.

49 Esto es lo que sucedió en la experiencia piloto que actualmente se desarrolla en Cataluña, tal como consta en el apartado séptimo del Conveni de colllaboració entre el Departament de Justícia i el Consell dels Il-lustres Col-legis d'Advocats de Catalunya, per a la implantació del programa de videocomunicacions entre les persones internes en centres penitenciaris i centres educatius de justícia juvenil i els seus advocats defensors, de 23 de març de 2017, 
por videoconferencia solo pueda hacerse desde el Colegio de Abogados y no desde el despacho del abogado o desde cualquier otro lugar en el que este se encuentre es que estas siempre dependerán del horario de aquel, además del que imponga el centro penitenciario.

Para concluir, no hemos de olvidar que, aunque estas comunicaciones, al igual que sucede actualmente con las orales (presenciales), deben registrarse por orden cronológico en el libro correspondiente, consignándose el nombre y apellidos de los comunicantes del interno, el número de la causa y el tiempo de duración de la visita (art. 48.1.3 $\left.{ }^{\mathrm{a} P}\right)^{50}$, esta constancia no puede suponer quebrar la confidencialidad de las mismas, por lo que estas no podrán ser oídas ni grabadas por la Administración Penitenciaria, más allá de en los casos en los que ello se permite legalmente.

\subsection{Otras cuestiones}

Finalmente, conviene examinar otras cuestiones que pueden tener una gran trascendencia en el desarrollo de las comunicaciones por videoconferencia de los internos con el abogado defensor o con el abogado expresamente llamado en relación con asuntos penales.

Así, en primer lugar, cabe preguntarse qué sucede en caso de que los equipos de videoconferencia instalados en el centro penitenciario no sean suficientes para atender la demanda. En este sentido, no hemos de olvidar que, como ya hemos dicho anteriormente, el uso de estos equipos trasciende el objeto de este trabajo, extendiéndose también a otros ámbitos como, por ejemplo, la celebración de actuaciones

p. 5, cuando dice que "prèviament a l'entrada en funcionament de l'agenda digital, l'horari de funcionament dels videolocutoris serà únicament de matí, de 9.15 h a 13.15 hores, de dilluns a divendres no festius. L'entrada en funcionament de l'agenda digital possibilitarà també un horari de tarda, de 15.30 a 19.30 hores".

50 Al respecto vid. el apartado undécimo del Conveni de col·laboració entre el Departament de Justícia i el Consell dels Il-lustres Col·legis d'Advocats de Catalunya, per a la implantació del programa de videocomunicacions entre les persones internes en centres penitenciaris i centres educatius de justícia juvenil i els seus advocats defensors, de 23 de març de 2017, pp. 7 y 8. 
judiciales, comunicaciones entre internos y familiares y consultas médicas. Lógicamente, este problema será más frecuente que surja cuanto mayor sea la demanda del sistema y menos equipos existan, por lo que los recursos materiales juegan aquí un papel trascendental. No obstante, entendemos que, a falta de equipos suficientes, debe tener preferencia, por este orden, la celebración de consultas médicas urgentes (lo que no parece lo más probable que suceda en la práctica), la celebración de actuaciones judiciales, las comunicaciones de los internos con el abogado defensor o con el abogado expresamente llamado en relación con asuntos penales, y, en último lugar, las comunicaciones entre internos y familiares ${ }^{51}$.

También hemos de plantearnos quién ha de sufragar el uso de esta tecnología. En este sentido, ha de tenerse en cuenta que, en relación con las comunicaciones telefónicas, se establece que el importe de la llamada será satisfecho por el interno, salvo cuando se trate de la comunicación prevista en el art. 41.3 RP, es decir, salvo la llamada para que el interno pueda comunicar inmediatamente a su familia y abogado su ingreso en un centro penitenciario, así como su traslado a otro establecimiento en el momento del ingreso (art. 47.4 RP). En el caso de las comunicaciones por videoconferencia, al menos hasta ahora, su coste está siendo sufragado por la Administración Pública o por los Colegios de $\operatorname{Abogados}^{52}$, pero no

51 En contra se pronuncia el apartado décimo del Conveni de col-laboració entre el Departament de Justícia i el Consell dels Il-lustres Col·legis d'Advocats de Catalunya, per a la implantació del programa de videocomunicacions entre les persones internes en centres penitenciaris i centres educatius de justícia juvenil i els seus advocats defensors, de 23 de març de 2017, p. 7, que da prioridad a las comunicaciones entre internos y familiares frente a las de los internos con sus abogados cuando dice que "cada centre penitenciari disposarà de tres espais de VCO: un es destinarà a les comunicacions judicials (sala de VCO), un altre a les VCO amb advocats (locutori 1) i l'altre a les comunicacions amb familiars (locutori 2). En cas que calgui, i sempre que estigui lliure, el locutori 2 es podrà utilitzar per a comunicacions judicials i amb lletrats. En el cas que els dos locutoris i la sala estiguin ocupats per agenda i es produeixi una urgència judicial, aquesta s'haurà d'acomodar dins del locutori 1, de manera que es preservin sempre les comunicacions familiars previstes”.

52 Según consta en el Acta de la Subcomisión de Derecho Penitenciario del GGAE de 11 de abril de 2014, pp. 4 y 5, disponible en http://www.derechopenitenciario.com/comun/fichero.asp?id=3991 (consultado el 1 de julio de 2019), el coste de estos proyectos pilotos corre, al menos por ahora, "a costa de los colegios de abogados [...] ya que la Administración no va a pagar 
es descabellado pensar que en un futuro próximo, en la medida que pueda extenderse este servicio, el mismo deje de ser gratuito para el interno o para su abogado ${ }^{53}$. Por ello, a nuestro juicio, se debería contemplar expresamente algo parecido a lo que actualmente dispone el art. 123.1 LECrim en relación con el derecho a la traducción e interpretación, de forma que los gastos de la videoconferencia sean sufragados por la Administración.

Por otro lado, hemos de advertir que el sistema actual no prevé la posibilidad de que el abogado pueda mostrar documentos a su defendido por vía telemática, por lo que en estos casos, deberá desplazarse personalmente hasta el centro penitenciario con los documentos impresos o, muy excepcionalmente, en formato electrónico, posibilidad esta última que actualmente también se está experimentado en algunos centros penitenciarios de nuestro país como proyecto piloto.

\section{Conclusiones}

Las comunicaciones por videoconferencia, en general, y las de los internos con el abogado defensor o con el abogado expresamente llamado en relación con asuntos penales, en particular, deberían regularse en la LOGP y/o en el RP, que actualmente son ajenos a la existencia de este medio de comunicación, además de desarrollarse en las Instrucciones que desde ese momento en adelante dictase la Secretaría General de Instituciones Penitenciarias.

Estas comunicaciones deben ser complementarias, no sustitutivas, de las actualmente previstas en la LOGP y en el RP, es decir, de las comunicaciones orales, presenciales y telefónicas, y escritas, y, en el caso de las de los internos con el abogado defensor o con el abogado expresamente llamado en relación con asuntos penales, constituyen una

ni un duro. (Instituciones Penitenciario [sic.] y la Fundación del CGAE) [...] y la experiencia piloto tendrá lugar en mayo o junio con un coste de 9.000 euros por Colegio".

53 Así sucede en otros países de nuestro entorno, como, por ejemplo, en Estados Unidos. 
forma de garantizar el ejercicio del derecho a la defensa y a la asistencia de letrado en el proceso penal, por lo que deben tener la protección que establece el art. 48.3 RP.

Precisamente por este motivo es necesario adoptar medidas como las que se proponen en este trabajo para el desarrollo de las mismas, de forma que su solicitud sea tremendamente ágil y sencilla, el abogado pueda intervenir en la videoconferencia desde su despacho o cualquier otro lugar donde se encuentre, y exista un número adecuado de recursos materiales y humanos que permitan que la periocidad y duración de este tipo de comunicaciones no sea vea lastrada por la falta de equipos o funcionarios. Del mismo modo, la gratuidad del sistema para el interno y su abogado, así como la posibilidad de que este pudiera mostrar documentos a su defendido por vía telemática, contribuirían enormemente al uso de la videoconferencia en las comunicaciones de los internos con el abogado defensor o con el abogado expresamente llamado en relación con asuntos penales.

\section{Bibliografía}

FERNÁNDEZ DÍAZ, Carmen Rocío. Internet Behind Bars: Reality or Utopia? En: OLIVEIRA, Lídia; GRAÇA, Daniela (eds.). Infocommunication Skills as a Rehabilitation and Social Reintegration Tool for Inmates. Hershey: IGI Global, 2019. p. 1-23.

GUTIÉRREZ BARRENENGOA, Ainhoa. La utilización de la videoconferencia en la Administración de Justicia. En: HERRÁN ORTIZ, Ana Isabel; EMALDI CIRIÓN, Aitziber; ENCISO SANTOCILDES, Marta (Eds.), Derecho y Nuevas Tecnologías. Bilbao: Universidad de Deusto, 2010. v. 2, p. 121-134.

JIMENO BULNES, Mar (Coord.). La cooperación judicial civil y penal en el ámbito de la Unión Europea: instrumentos procesales. Barcelona: Bosch, 2007.

JIMENO BULNES, Mar (Dir.); MIGUEL BARRIO, Rodrigo (Coord.). Espacio judicial europeo y proceso penal. Madrid: Tecnos, 2018.

JORDÁN DÍAZ-RONCERO, María José. Análisis de la implantación y eficacia de la videoconferencia en el proceso penal español: hacia una modernización de nuestro sistema de justicia penal. Tesis Doctoral (Programa de Doctorado en Derecho, 
Empresa y Justicia) - Universidad de Valencia, Valencia, 2014. Disponible en: <http://roderic.uv.es/handle/10550/44107>. Consultado el: 1 jul. 2019.

MARCOS MADRUGA, Florencio de. Las nuevas tecnologías en los centros penitenciarios y sus implicaciones jurídicas. En: MATA Y MARTÍN, Ricardo M. (Dir.); JAVATO MARTÍN, Antonio María (Coord.). Sistema penitenciario y nuevas tecnologias. Valladolid: Lex Artis, 2014. p. 225-249.

MAPELLI CAFFARENA, Borja; BARAS GONZÁLEZ, Marcos. Sistemas de videoconferencia entre abogados y personas privadas de libertad. La Ley Penal: Revista de Derecho Penal, Procesal y Penitenciario, Madrid, n. 124, p. 1-7, 2017.

MARTÍN MORAL, María Flora. La utilización del sistema de videoconferencia en el marco de las instituciones penitenciarias. En: MATA Y MARTÍN, Ricardo M. (Dir.); JAVATO MARTÍN, Antonio María (Coord.). Sistema penitenciario y nuevas tecnologias. Valladolid: Lex Artis, 2014. p. 45-60.

RODRÍGUEZ ÁLVAREZ, Ana; GARCÍA MONTEAGUDO, Alexandre. La intervención de las comunicaciones telefónicas y telemáticas entre el abogado y el investigado. En: BUENO DE MATA, Federico (Dir./Coord.). FODERTICS 6.0: los nuevos retos del derecho ante la era digital. Granada: Comares, 2017. p. 183-194.

TIRADO ESTRADA, Jesús José. Videoconferencia, cooperación judicial internacional y debido proceso. Revista de la Secretaría del Tribunal Permanente de Revisión, Asunción, v. 5, n. 10, p. 153-173, 2017. http://dx.doi.org/10.16890/ rstpr.a5.n10.p153

VALBUENA GONZÁLEZ, Félix. Proceso penal y videoconferencia. En: HERRÁN ORTIZ, Ana Isabel; EMALDI CIRIÓN, Aitziber; ENCISO SANTOCILDES, Marta (Eds.), Derecho y Nuevas Tecnologías. Bilbao: Universidad de Deusto, 2010. v. 3, p. 83-95.

VIDA FERNÁNDEZ, José. Análisis y propuestas para garantizar el derecho a la asistencia sanitaria de los internos en instituciones penitenciarias. La Ley Penal: Revista de Derecho Penal, Procesal y Penitenciario, Madrid, n. 62, p. 1-19, 2009. 


\section{Informações adicionais e declarações dos autores (integridade científica)}

Declaração de conflito de interesses (conflict of interest declaration): o autor confirma que não há conflitos de interesse na realização das pesquisas expostas e na redação deste artigo.

Declaração de autoria e especificação das contribuições (declaration of authorship): todas e somente as pessoas que atendem os requisitos de autoria deste artigo estão listadas como autores; todos os coautores se responsabilizam integralmente por este trabalho em sua totalidade.

Declaração de ineditismo e originalidade (declaration of originality): o autor assegura que o texto aqui publicado não foi divulgado anteriormente em outro meio e que futura republicação somente se realizará com a indicação expressa da referência desta publicação original; também atesta que não há plágio de terceiros ou autoplágio.

\section{Dados do processo editorial}

(http://www.ibraspp.com.br/revista/index.php/RBDPP/about/editorialPolicies)

- Recebido em: 09/07/2019

- Controle preliminar e verificação de plágio: 12/07/2019

- Avaliação 1: 24/07/2019

- Avaliação 2: 25/07/2019

- Avaliação 3: 27/07/2019

- Decisão editorial preliminar: 27/08/2019

- Retorno rodada de correções: 10/09/2019

- Decisão editorial final: 24/09/2019
Equipe editorial envolvida

- Editor-chefe: 1 (VGV)

- Editora-associada: 1 (CC)

- Revisores: 3 


\section{COMO CITAR ESTE ARTIGO:}

GARCÍA MOLINA, Pablo. Las comunicaciones por videoconferencia de los internos con el abogado defensor o con el abogado expresamente llamado en relación con asuntos penales. Revista Brasileira de Direito Processual Penal, Porto Alegre, v. 5, n. 3, p. 1219-1254, set./dez. 2019. https://doi.org/10.22197/rbdpp.v5i3.255

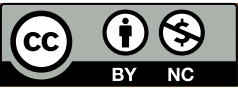

Esta obra está licenciada com uma Licença Creative Commons Atribuição-NãoComercial 4.0 Internacional. 